\title{
Income Inequities in Health Care Utilization among Adults Aged 50 and Older
}

\author{
Margaret J. Penning \\ Department of Sociology, University of Victoria
}

Chi Zheng

Centre on Aging, University of Victoria

\begin{abstract}
RÉSUMÉ
L'accès équitable et l'utilisation des services de santé sont des objectifs primaires pour de nombreux systèmes de soins de santé, en particulier dans les pays dotés de systèmes universels financés par l'État. Malgré des incertitudes quant aux conséquences potentiellement défavorables de la politique de soins de santé et d'autres réformes dans les années 1990 , il reste difficile de savoir si et comment les inégalités de revenus dans l'utilisation des services ont altérés ensuite. Cette étude portait sur l'impact du revenu sur l'utilisation des médecins et des hôpitaux de 1992 à 2002 chez les adultes âgés de 50 ans ou plus en la Colombie-Britannique. Ceux qui ont des revenus plus faibles ont été trouvés d'être moins susceptibles d'accéder aux médecins généralistes et les services de spécialistes, mais étaient plus susceptibles d'accéder aux services hospitaliers. Les disparités liées au revenu dans l'accès aux soins de médecins a augmenté au fil du temps, tandis que l'accès aux soins de l'hôpital a diminué. Le volume de soins de médécins géneralistes et des soins de l'hôpital étaient inversement proportionnelle au revenu; ces différences ont augmenté en ce qui concerne les services des MGs seulement. Les résultats de baisses dans l'accès aux soins à l'hôpital, accompagné par des disparités croissantes de revenus liés à l'accès aux services de médecins, montrent que les inégalités augmentent dans le système de soins de santé canadien.
\end{abstract}

\begin{abstract}
Equitable access to and utilization of health services is a primary goal for many health care systems, particularly in countries with universal publicly funded systems. Despite concerns regarding potentially adverse implications of the 1990 s' $^{\prime}$ health care policy and other reforms, whether and how income inequalities in service utilization changed remains unclear. This study addressed the impact of income on physician and hospital utilization from 1992-2002 among adults aged 50 and older in British Columbia. Those with lower incomes were found less likely to access general practitioner and specialist services but more likely to access hospital services. Income-related disparities in physician care increased over time; hospital care declined. Volume of GP and hospital care was inversely associated with income; these differences increased regarding GP services only. Findings of declines in hospital-care access, accompanied by increasing incomerelated disparities in physician-services access, show that inequities are increasing within Canada's health care system.
\end{abstract}

Manuscript received: / manuscrit reçu : 22/05/14

Manuscript accepted: / manuscrit accepté : 06/06/15

Mots clés: vieillissment, données de gestion, équité, réforme de soins de santé, utilisation de hôpitaux, utilisation des médecins

Keywords: aging, administrative data, equity, health care reform, hospital utilization, physician utilization

La correspondance et les demandes de tirés-à-part doivent être adressées à: / Correspondence and requests for offprints should be sent to:

Margaret J. Penning, Ph.D.

Department of Sociology

University of Victoria

PO Box 1700 STN CSC

Victoria, BC V8W 2Y2

(mpenning@uvic.ca)

Equitable access to health services is a primary goal of many health care systems and, particularly, of universal publicly funded systems developed on the premise that all citizens should have reasonable access to health care services on the basis of need, rather than on ability to pay (Curtis \& MacMinn, 2008; Dunlop, Coyte, \& McIsaac, 2000). In Canada, for example, post-World War II concerns regarding high costs of health care and 
consequent inequalities in access gradually led to the development of a universal national health insurance program (i.e., Medicare). The program was initiated in 1957 when the Hospital Insurance and Diagnostic Services Act was introduced, providing national coverage of hospital services. In 1965, the Medical Care Act was implemented, extending federal funding to physician services. Finally, in 1984, the Canada Health Act reinforced the principle of equitable access for all necessary physician and hospital services: "The primary objective of Canadian health care policy is to protect, promote and restore the physical and mental well-being of residents of Canada and to facilitate reasonable access to health services without financial or other barriers" (House of Commons, Canada, 1984, p. 1).

Given the explicit equity objectives of Canadian health care policy, over the years, researchers have focused considerable attention on determining whether removing financial barriers enhanced socioeconomic equity in the use of health care services, with equity generally considered evident when medically defined health needs rather than socioeconomic factors affect utilization (Allin, Grignon, \& Le Grand, 2010). Whereas findings obtained from studies conducted before the introduction of national health insurance frequently documented economic disparities in health service utilization favouring more advantaged socioeconomic groups (Badgley, 1991), those conducted in the decades immediately following the introduction of national health insurance suggested that, although universal health insurance in Canada had not yet succeeded in eliminating economic constraints that affected access to health services (Badgley, 1991), such disparities had at least been reduced (Birch \& Abelson, 1993; Birch, Eyles, \& Newbold, 1993; Broyles, Manga, Binder, Angus, \& Charette, 1983; Enterline, Salter, McDonald, \& McDonald, 1973; Manga, 1987; Manga, Broyles, \& Angus, 1987).

However, whereas the 1970s and 1980s can perhaps be characterized as an era of progress with regard to the socioeconomic equity objectives of Canadian health care policy, more recent literature has voiced concern regarding the implications of subsequent trends. During the early to mid-1990s, for example, increased governmental attention to issues of cost containment and deficit reduction (Birch \& Gafni, 2005; Eyles, Birch, \& Newbold, 1995) undertaken in the context of economic globalization and neo-liberal ideologies are widely noted to have generated health care reform and restructuring initiatives along market-oriented lines (Armstrong et al., 2003; Benoit, Zadoroznyj, Hallgrimsdottir, Treloar, \& Taylor, 2010; Randall \& Williams, 2006). These included limits on human resources (e.g., declines in the availability of physicians - see Lasser, Himmelstein, \& Woolhandler, 2006; Watson, Black, Peterson, Mooney, \& Reid, 2006; Watson, Heppner, Reid, Bogdanovic, \& Roos, 2005) and downsizing of hospital infrastructure (e.g., hospital bed closures - see Carriere, Roos, \& Dover, 2000).

Together with the declines in public health care spending that took place in Canada during the early to mid-1990s (see Canadian Institute for Health Information [CIHI], 2000, 2008; Thorlby, 2011), the overall number of physicians per capita also declined during this period (e.g., from a high of 191 per 100,000 population in 1993 to 184 per 100,000 population in 1997) before increasing once again over the course of the following decade (e.g., reaching 203 per 100,000 population in 2010 - Canadian Medical Association [CMA], 2015). The number of hospital beds in Canada also declined steadily during and shortly after this period (Thorlby, 2011). As noted by Barer, Morgan, \& Evans (2003), for example, "hospital bed capacity fell (per capita) by about one-third between 1993/94 and 1999/2000" (p. 12) before beginning to stabilize again. Similar declines were evident in all provinces (Barer et al., 2003).

Other changes noted during this period included shifts in physician and hospital practice patterns (e.g., delisting of selected services, earlier discharges, transitions from inpatient to outpatient hospital care - see Birch \& Gafni, 2005; Hanratty, Zhang, \& Whitehead, 2007; Williams, 2007), tightening of eligibility criteria together with shifts to managed care (Randall \& Williams, 2006), and re-commodification through relocating selected services (e.g., pharmaceuticals, nursing care) outside the boundaries of Medicare (Deber, 2003; Williams, Deber, Barenek, \& Gildiner, 2001).

These and other welfare state reforms have been noted to threaten the universality of Canada's health care system (Williams et al., 2001), increase social and economic inequalities (Coburn, 2003; Frenette, Green, \& Picot, 2004; Teeple, 2000), and by implication, to increase poor health and the need for care. Research conducted during and after the 1990s provides some support for these concerns. For example, after controlling for health-related need, the overall probability of seeing a physician, whether general practitioner (GP) or specialist, has been found to be greater among those with higher incomes, despite the fact that the number of visits conditional on use is generally greater among the poor (Lasser et al., 2006; van Doorslaer, Masseria, \& OECD Health Equity Research Group, 2006).

Similarly, studies distinguishing GP from specialist services often (though not always - e.g., see Dunlop et al., 2000; McGrail, 2008; McIsaac, Goel, \& Naylor, 1997) have reported that, after adjusting for need, higher income is associated with a greater probability of contact with a GP, albeit fewer visits conditional on contact (Allin, 2008; Asada \& Kephart, 2007; Chan \& Austin, 2003; Curtis \& MacMinn, 2008; Nabalamba \& Millar, 2007; van Doorslaer, Masseria, \& Koolman, 2006). 
Higher income groups are also more likely to visit specialists (Curtis \& MacMinn, 2008; Dunlop et al., 2000; McGrail, 2008; Nabalamba \& Millar, 2007; van Doorslaer et al., 2006). Although some studies find no relationship with number of specialist visits conditional on use (Allin, 2008; Asada \& Kephart, 2007; Curtis \& MacMinn, 2008; Dunlop et al., 2000), others report greater conditional use among higher income groups (McGrail, 2008; van Doorslaer et al., 2006). Contradictory findings are also evident when it comes to hospital utilization. However, most studies report an inverse relationship, with poorer individuals more likely to be hospitalized (Allin, 2008; Curtis \& MacMinn, 2008; McGrail, 2008; Newbold, 2009; van Doorslaer et al., 2004; Yip, Kephart, \& Veugelers, 2002) with longer lengths of stay (Curtis \& MacMinn, 2008; McGrail, 2008; van Doorslaer et al., 2004; Yip, Kephart, \& Veugelers, 2002).

The vast majority of available studies, however, draw on cross-sectional (survey or administrative health) data. Comparison with studies conducted prior to the 1990s is instructive, and suggests that socioeconomic factors are likely continuing, if not increasing, their influence over access to selected aspects of health care service utilization. Similarly, comparisons of multiple cross-sections of data acquired at different points in time (e.g., see Curtis \& MacMinn, 2008; Eyles et al., 1995; McGrail, 2008) have led to conclusions that inequities in health-care utilization are apparent and, in some cases, (e.g., specialist services) these inequities have increased in recent years (Curtis \& MacMinn, 2008; McGrail, 2008). Ultimately, however, longitudinal analyses are required to accurately determine whether and how such relationships have shifted over time. Such studies are lacking (Macdonald et al., 2009). This is particularly the case when it comes to middleaged and older segments of the population who suffer from chronic conditions and have been identified as high users of physician and hospital services (DeCoster, Roos, \& Carriere, 1997; Reid et al., 2003; Roos, Burchill, \& Carriere, 2003) and, consequently, have become a focal point for health care reform initiatives designed to reduce health care costs and enhance opportunities for market-based alternatives for care.

In order to address these gaps in the research literature, this article reports the results of a series of analyses designed (1) to examine relationships between income levels and the use of medical health services (including physician and hospital care) among middle-aged and older adults in British Columbia, a Canadian province that exemplifies national health care policy and other reforms engaged in during the $1990 \mathrm{~s}^{1}$; and (2) to determine whether relationships between income levels and the use of these services changed over time during a period (1992-2002) characterized by the introduction of health care reforms and restructuring designed primarily to achieve economic objectives.

\section{Data and Methods}

\section{Data Source}

To address these questions, our analyses drew on provincial administrative health data regarding the use of physician and hospital services (i.e., Medical Services Plan Physician Payment Information and Hospital Discharge Abstracts Database) in the province of British Columbia. Administrative data are noted to be both reliable and valid for addressing questions concerning health care utilization (Roos, Nicol, \& Cageorge, 1987; Roos et al., 1993). Use of these data for this project was approved by the British Columbia Ministry of Health, British Columbia Linked Health Database (BCLHD) Data Stewards, and the University of Victoria Human Research Ethics Committee.

\section{Sampling}

The study cohort included all adults aged 50 and older who were residents in the province of British Columbia and registered to receive health services between January 1, 1992, and December 31, 2002. Overall, data were available for an average of 1.1 million individuals per year. Annual counts ranged from 945,902 in 1992 to 1,319,126 in 2002.

\section{Measurement}

Table 1 reports frequency distributions for all variables used in the analyses: health service use was the dependent variable; income and year were the primary independent variables; age, gender, rural-urban residence, and health status were included as control variables.

\section{Health Service Use}

Health service use was assessed based on physician (i.e., general practitioners, specialists) and inpatient hospital (acute and/or extended) care. For each health service utilization category, a binary incidence variable was constructed contrasting use versus non-use in any given year. In addition, a continuous (count) variable measured volume of use. The latter was considered conditional on use and was assessed using (a) number of visits made to GPs and specialists and (b) both the total number of hospitalizations and the total number of overnight stays in a hospital each year.

\section{Income}

Income data are not available at the individual level within the BCLHD. Consequently, an ecological measure was constructed in which income quintile rankings 
Table 1: Variable distributions (1992 data, $n=945,902)$

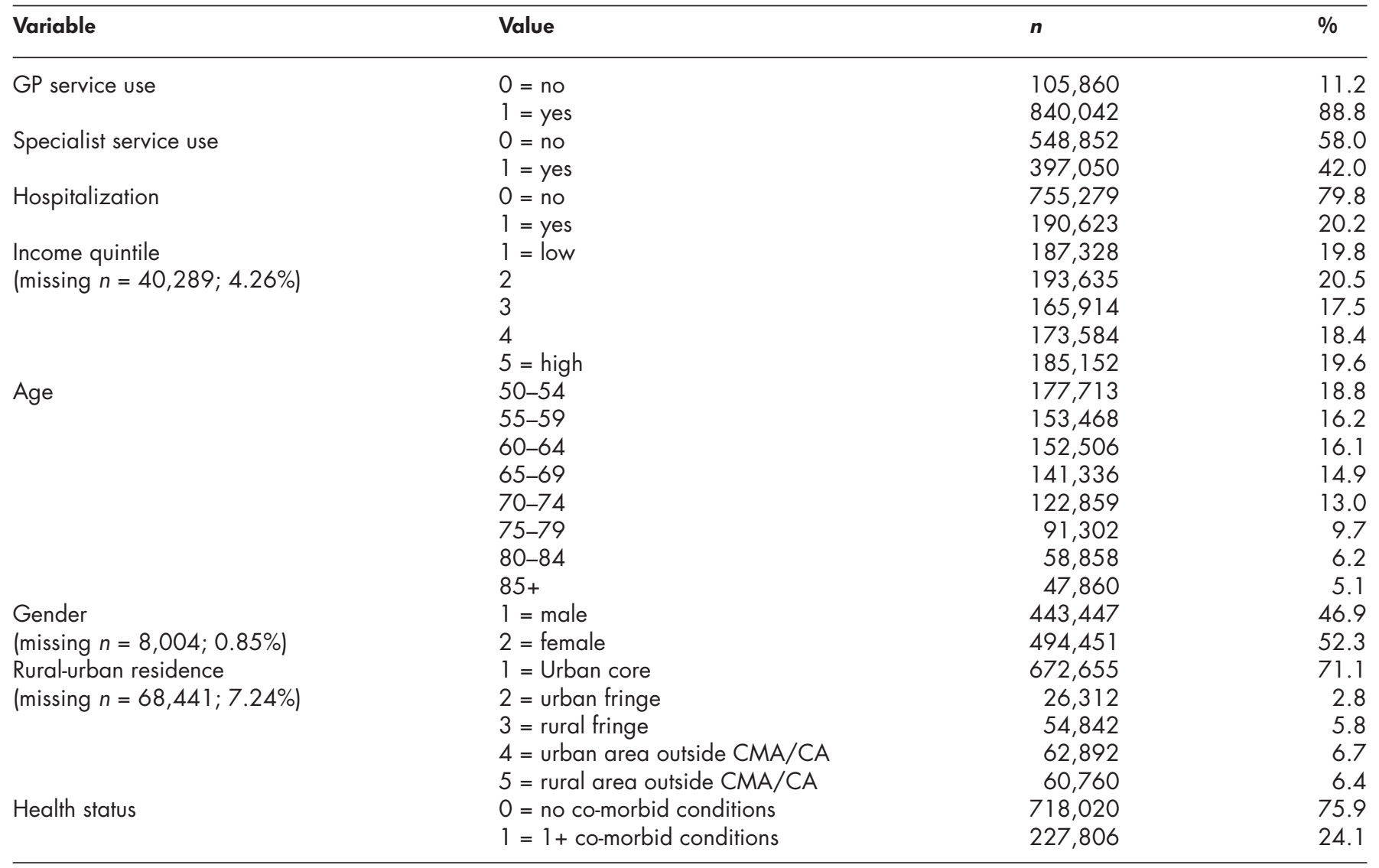

CMA/CA $=$ census metropolitan area or a census agglomeration.

were assigned using mean household income within enumeration areas of residence derived from Canadian census data. Income quintiles for any given year were based on the nearest census year, that is, quintiles from the 1996 census were applied to data representing 1994 through 1998. Although such measures have come under criticism (e.g., see Sin, Svenson, \& Man, 2001), utilization gradients across area-based income quintiles are similar to those obtained using individual-level household income data (Mustard, Derksen, Berthelot, \& Wolfson, 1999).

\section{Year of Study}

Year of study was assessed over an 11-year period: January 1, 1992-December 31, 2002.

\section{Control Variables}

Control variables included age (in years), gender $(1=M$, $2=\mathrm{F}$ ), rural-urban residence, and health status. Ruralurban residence was operationalized using the Statistics Canada rurality index (Statistics Canada, 1997; Pitblado et al., 1999; Racher, Vollman, \& Annis, 2004). This index draws on postal code information to classify areas of residence into five categories ranging from most to least urban: urban core, urban fringe, rural fringe, urban (small town), and rural. Health status was measured using a version of the Charlson Comorbidity Index (CCI - see Charlson, Pompei, Ales, \& MacKenzie, 1987), a diagnosis- and procedure-based measure originally designed to estimate risk of oneyear mortality attributable to co-morbidity in a longitudinal study of hospital patients. The CCI assesses morbidity based on the number and severity of various chronic conditions (e.g., congestive heart failure, cerebrovascular disease, dementia, chronic pulmonary disease, diabetes, leukemia, lymphoma,). Each disease was assigned a weight ( 1 to 6 ) based on mortality risk. A score was then calculated by computing the total of the weights obtained for all conditions (coded using ICD9-CM diagnoses codes) reported in the provincial Medical Services Plan (MSP) records for each client each year, with a higher score indicating more severe co-morbidity (Schneeweiss et al., 2001). Prior research suggests that this index provides a reliable and valid measure for use in longitudinal studies and in research drawing on administrative data (Hall, Ramachandran, Narayan, Jani, \& Vijayakumar, 2004). In this study, we used a modified index that we developed using algorithms drawn from Quan et al. (2005) and physician, 
rather than hospital claims, data. Individuals without records (non-service-users) or whose records did not include diagnosis codes were assigned a score of 0 .

\section{Data Analytic Procedures}

Multivariate analyses were conducted using SAS logistic regression software (SAS PROC GENMOD with a binomial distribution and logit link) and generalized estimating equations (GEE - SAS PROC GENMOD with studyid as the repeating variable and an exchangeable correlation structure). The former were used to assess the impact of income, net of other determinants, on use versus non-use of each health service; the latter were used to assess extent or volume of service use among users only. For each outcome measure, the main effects model was tested first. To address the possibility of income-related changes in health care utilization, the second model also included an income quintile $\times$ year interaction term. Given the large number of records involved, analyses of GP visits were conducted using a 10 per cent randomly selected subsample and a dichotomous co-morbidity measure; all other analyses employed the total sample and a continuous co-morbidity measure. A significance level of $p<.001$ was employed.

\section{Results}

\section{General Practitioners}

In 1992, 88.8 per cent of those aged 50 and over who were registered to receive services saw a GP at least once. This increased to 89.7 per cent by 2001. Among those who visited a GP at least once, the average number of visits made across all 11 years of the study period was $13.03(S D=14.87$; median $=8$ ).

Logistic regression analyses conducted to examine the impact of income and other social determinants on use versus non-use of GP services over the 11-year study period revealed that those in lower to middle income groups (i.e., quintiles 1 to 3 ) were significantly less likely to make use of GP services than were those in the highest income group (Q5), with no significant difference evident when comparing quintiles 4 and 5 (see Table 2). Conversely, year was not significantly related to service use. Other health and social factors significantly related to GP service use included age, gender, rurality, and health status. Older adults, women, and those living in more urban areas (i.e., R1-R4) as well as those with poorer health status were more likely to draw on GP services than were those in the reference categories. Tests for the presence of an interaction effect

Table 2: GP service use versus non-use

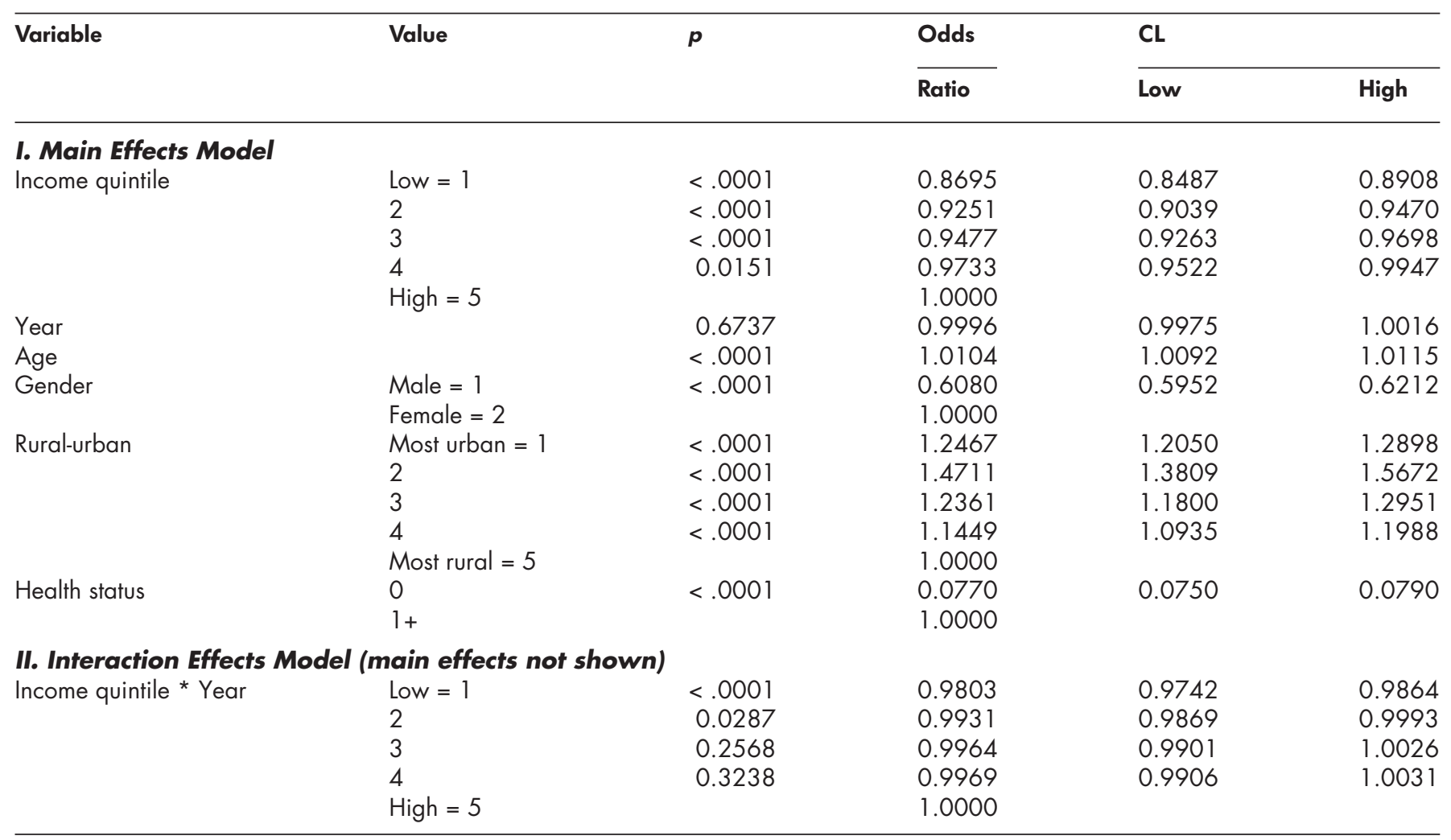

Odds ratios calculated from parameter estimates for main effects and interaction models, SAS PROC GENMOD modelling outcome as receipt of service (binomial distribution, logit link). $p=Z$ score probability; $C L=$ Wald $95 \%$ confidence limit. 
involving income and year revealed that differences in the likelihood of use between lower and higher income groups were greater in later years of the decade. Compared to those in the highest income quintile, those in the lowest income group were significantly less likely to receive GP services as the decade progressed. Thus, income inequalities in whether or not people accessed GP services appear to have increased somewhat over the study period, to the increasing disadvantage of those in the lowest income group.

Next, we looked at the impact of income and other social and health factors on the number of GP visits made by those who had used such services at least once over the 11-year study period. Here, significant predictors of a greater number of visits included both income and year (see Table 3). Those in lower to middle income quintiles (Q1-Q3) made significantly more visits to GPs than did those in the highest income group (Q5), with no difference evident between quintiles 4 and 5 . As well, the number of GP visits increased as the decade progressed. Age (older adults made more visits), gender (women made more visits), rurality (those living in more urban areas [i.e., R1 and R4] made more visits than those living in the most rural area (R5), and health status (those with higher CCI scores made more visits) also influenced volume of use. Finally, there was also a significant interaction evident between income and year with lower income groups $(Q 1, Q 2)$ showing a somewhat greater increase in the volume of GP service use over the course of the decade when compared to those in Q5.

\section{Specialists}

From 1992 through 2002, from 42 per cent (in 1991) to 44.7 per cent (in 2001) of those aged 50 and older who were registered to receive services in British Columbia, used a specialist at least once. Among those who visited a specialist at least once, the mean number of visits made across all 11 years was 4.43 $(S D=6.45$; median $=2)$ and ranged from a low of 3.65 visits in $1992(S D=4.66$; median $=2)$ to a high of 7.11 visits in $2002(S D=10.06$; median $=4)$.

Significant predictors of specialist use once again included both income and year (see Table 4). Those in lower through upper middle income groups (Q1-Q4) were significantly less likely to make use of specialist services than those in the highest income group (Q5). In addition, as years progressed, the likelihood of specialist use increased. Age, gender, rurality, and health status were once again related to use in the same direction as was found for GP services. As well, the

Table 3: Number of GP visits conditional on use

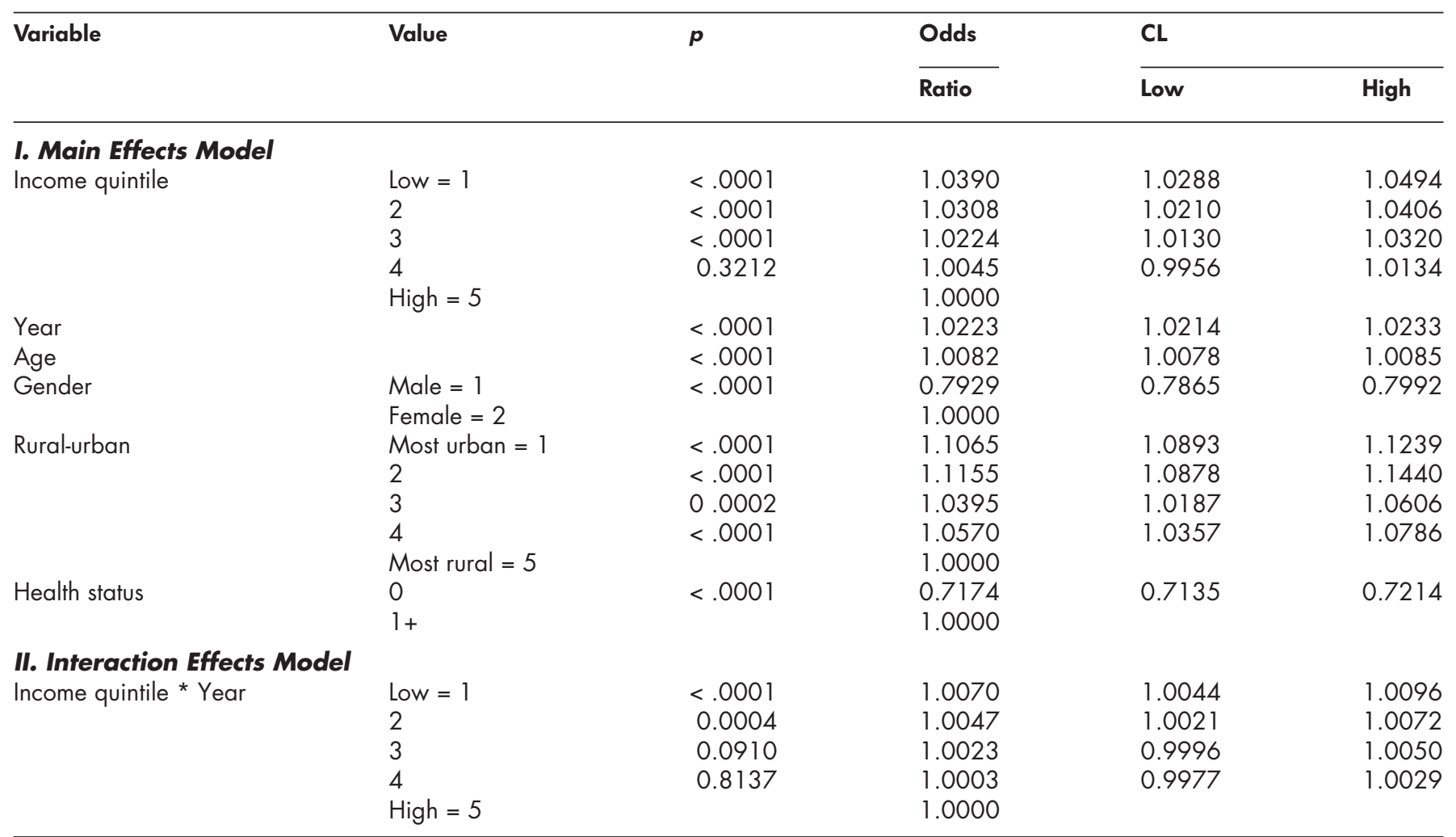

Odds ratios calculated from parameter estimates for main effects and interaction models, SAS PROC GENMOD modelling outcome as annual number of visits (negative binomial distribution, log link). $p=Z$ score probability; $C L=$ Wald $95 \%$ confidence limit. 
Table 4: Specialist service use versus non-use

\begin{tabular}{|c|c|c|c|c|c|}
\hline Variable & Value & $p$ & $\begin{array}{l}\text { Odds } \\
\text { Ratio }\end{array}$ & \multicolumn{2}{|l|}{$\mathrm{CL}$} \\
\hline \multicolumn{6}{|l|}{ I. Main Effects Model } \\
\hline \multirow[t]{3}{*}{ Income quintile } & Low $=1$ & $<.0001$ & 0.8895 & 0.8754 & 0.9038 \\
\hline & 2 & $<.0001$ & 0.9224 & 0.9081 & 0.9370 \\
\hline & 3 & $<.0001$ & 0.9475 & 0.9329 & 0.9623 \\
\hline Year & & $<.0001$ & 1.0125 & 1.0111 & 1.0139 \\
\hline Age & & $<.0001$ & 1.0201 & 1.0195 & 1.0207 \\
\hline \multirow[t]{2}{*}{ Gender } & Male $=1$ & $<.0001$ & 0.8851 & 0.8738 & 0.8966 \\
\hline & Female $=2$ & & 1.0000 & & \\
\hline \multirow[t]{2}{*}{ Rural-urban } & Most urban $=1$ & $<.0001$ & 1.3254 & 1.2940 & 1.3576 \\
\hline & 2 & $<.0001$ & 1.4534 & 1.3970 & 1.5119 \\
\hline \multicolumn{6}{|c|}{ II. Interaction Effects Model (main effects not shown) } \\
\hline \multirow[t]{5}{*}{ Income quintile * Year } & Low $=1$ & $<.0001$ & 0.9901 & 0.9860 & 0.9943 \\
\hline & 2 & 0.0002 & 0.9920 & 0.9879 & 0.9963 \\
\hline & 3 & 0.0926 & 0.9963 & 0.9920 & 1.0006 \\
\hline & 4 & 0.5659 & 0.9988 & 0.9945 & 1.0030 \\
\hline & $\mathrm{High}=5$ & & 1.0000 & & \\
\hline
\end{tabular}

Odds ratios calculated from parameter estimates for main effects and interaction models, SAS PROC GENMOD modelling outcome as receipt of service (binomial distribution, logit link). $p=Z$ score probability; $C L=$ Wald $95 \%$ confidence limit.

income $x$ year interaction effect was also statistically significant with those in the two lowest quintiles (Q1 and Q2) somewhat less likely to see increased specialist use over time when compared to those in the highest income quintile (Q5). Thus, income inequalities in whether or not people accessed specialist care appear to have increased over the study period, once again to the disadvantage of those in lower income groups.

Next, we looked at the impact of income and other factors on the number of specialist visits made by those who had used such services over the study period (see Table 5). Here, testing the main effects model indicated that year, but not income, was significantly associated with a greater number of visits. As the years progressed, the number of specialist visits increased. Age (older adults made more visits), gender (males made more specialist visits), rurality (with those living in more urban areas [R1-R3] having more specialist visits than those in the most rural [R5] areas), and health status (those with higher scores on the Charlson index had more visits) also were significantly related to the number of visits. However, there was no significant interaction between income and year, suggesting that the increased number of visits observed over the study period was similar across income levels.

\section{Hospitalizations}

From 1992 to 2002, from 20.5 per cent (in 1993) to 17.7 per cent (in 2002) of those aged 50 and older received hospital care. Among those who were hospitalized, the mean number of hospitalizations per year was $1.59(S D=1.18$; median $=1)$. The average number of hospitalizations ranged from a low of 1.54 in $2002(S D=1.14$; median $=1)$ to a high of 1.64 hospitalizations in $1993(S D=1.20$; median $=1)$. Among those who visited a hospital at least once during this period, the average number of days spent in hospital was $19.11(S D=131.82$; median $=2)$ and ranged from a low of 8.67 days in $2002(S D=75.53$; median $=1)$ to a high of 22.84 days in $1993(S D=145.76$; median $=3$ ).

Significant predictors of whether or not individuals were hospitalized during the study period included both income and year (Table 6). In contrast with the results obtained with respect to physician services (both GP and specialists), those in lower through upper middle income quintiles (i.e., Q1-Q4) were significantly more likely to be hospitalized than those in the highest income quintile (Q5). In addition, as the years passed, the likelihood of hospitalization declined. Older age, male gender, more rural residence, and poorer health status were associated with a greater likelihood of 
Table 5: Number of specialist visits conditional on use

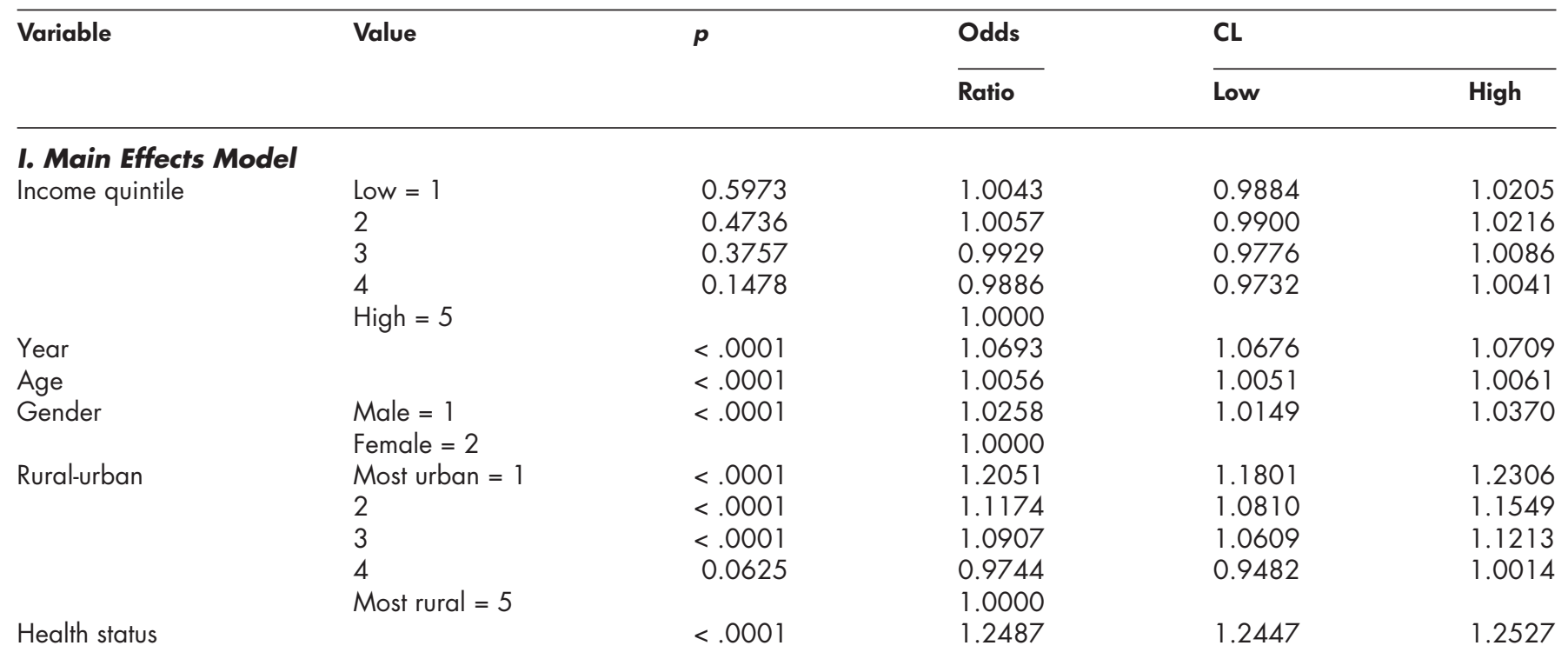

II. Interaction Effects Model (main effects not shown) Income quintile * Year (ns, $p=0.6896)$

Odds ratios calculated from parameter estimates for main effects and interaction models, SAS PROC GENMOD modelling outcome as annual number of visits (negative binomial distribution, log link). $p=Z$ score probability; $C L=$ Wald $95 \%$ confidence limit; $n$ s $=$ not significant.

hospitalization during this period. Once again, however, no significant income-by-year interaction was evident, suggesting that declines in the likelihood of hospitalization that were observed over the course of the decade were similar across income groups. Thus, income inequalities in whether or not people accessed hospital care did not change over the course of the study period.

Next, we looked at the impact of income and year on the number of hospitalizations among those hospitalized over the 11-year study period (see Table 7). In these analyses, both income and year were significantly related: those in the two lowest income quintiles (Q1, Q2) had significantly more hospitalizations than did those in the highest quintile (Q5). As well, as the years progressed, the number of hospitalizations decreased somewhat. Older individuals, males, those living in more-rural areas, and those with poorer health status had a greater number of hospitalizations than others. However, controlling for age, gender, rurality, and health status revealed no significant income-by-year interaction, thereby indicating once again that the impact of income on this aspect of hospital use did not change over the course of the decade. Thus, declines in the number of hospitalizations were similar across income groups.

Finally, analyses conducted to assess changes in the impact of income on the length of hospital stay among those who had at least one stay over the 11-year study period revealed no significant differences in length of hospital stays across income groups. As well, as the years passed, the number of days spent in hospital care changed little (see Table 8). Those with poorer health status had longer hospital stays. Older adults and women, when hospitalized, also spent more days in hospital care. Finally, no significant interaction was found between income and year, suggesting that the impact of income on lengths of hospital stay changed little over the course of the decade.

\section{Discussion}

This study examined relationships between income levels and the use of publicly funded health services (i.e., physicians and hospital care) by middle-aged and older adults resident in the province of British Columbia from 1992 through 2002. Its focus was on the impact of income inequalities in access to and utilization of health services and particularly, on whether relationships between income levels and health services use changed over the course of this decade, a period characterized by increasing income inequalities and the introduction of health care restructuring and reform along neo-liberal lines.

Findings indicating that, with health status differences taken into account, those with lower incomes were less likely to access GP and especially specialist services but more likely to access hospital services than those with higher incomes, corroborate those reported in several other studies for the population as a whole and 
Table 6: Hospital use versus non-use

\begin{tabular}{|c|c|c|c|c|c|}
\hline \multirow[t]{2}{*}{ Variable } & \multirow[t]{2}{*}{ Value } & \multirow[t]{2}{*}{$p$} & \multirow{2}{*}{$\begin{array}{l}\text { Odds } \\
\text { Ratio }\end{array}$} & \multicolumn{2}{|l|}{ CL } \\
\hline & & & & Low & High \\
\hline \multicolumn{6}{|c|}{ I. Main Effects Model } \\
\hline \multirow[t]{5}{*}{ Income quintile } & Low $=1$ & $<.0001$ & 1.0496 & 1.0305 & 1.0691 \\
\hline & 2 & 0.0015 & 1.0302 & 1.0115 & 1.0494 \\
\hline & 3 & $<.0001$ & 1.0420 & 1.0231 & 1.0613 \\
\hline & 4 & 0.0004 & 1.0333 & 1.0148 & 1.0523 \\
\hline & High $=5$ & & 1.0000 & & \\
\hline Year & & $<.0001$ & 0.9873 & 0.9856 & 0.9890 \\
\hline Age & & $<.0001$ & 1.0367 & 1.0360 & 1.0373 \\
\hline \multirow[t]{2}{*}{ Gender } & Male = 1 & $<.0001$ & 1.0562 & 1.0424 & 1.0704 \\
\hline & Female $=2$ & & 1.0000 & & \\
\hline \multirow[t]{5}{*}{ Rural-urban } & Most urban $=1$ & $<.0001$ & 0.8947 & 0.8725 & 0.9174 \\
\hline & 2 & 0.1598 & 0.9713 & 0.9328 & 1.0116 \\
\hline & 3 & $<.0001$ & 0.9181 & 0.8870 & 0.9505 \\
\hline & 4 & $<.0001$ & 1.0772 & 1.0424 & 1.1134 \\
\hline & Most rural $=5$ & & 1.0000 & & \\
\hline Health status & & $<.0001$ & 1.9263 & 1.9092 & 1.9435 \\
\hline
\end{tabular}

II. Interaction Effects Model (main effects not shown)

Income quintile * Year (ns, $p=0.0851$ )

Odds ratios calculated from parameter estimates for main effects and interaction models, SAS PROC GENMOD modelling outcome as receipt of service (binomial distribution, logit link). $p=Z$ score probability; $C L=$ Wald $95 \%$ confidence limit; ns $=$ not significant.

conducted during the same time period (e.g., Allin, 2008; McGrail, 2008; van Doorslaer et al., 2004). So too do findings indicating that among those who accessed such services, the volume of GP and hospital (but not specialist) services utilized was inversely associated with income (Lemstra, Mackenbach, Neudorf, \& Nannapaneni, 2009; van Doorslaer et al., 2004). Findings of this nature indicate that the patterns generally reported with respect to the population as a whole also apply when it comes to middle-aged and

Table 7: Number of hospitalizations conditional on use

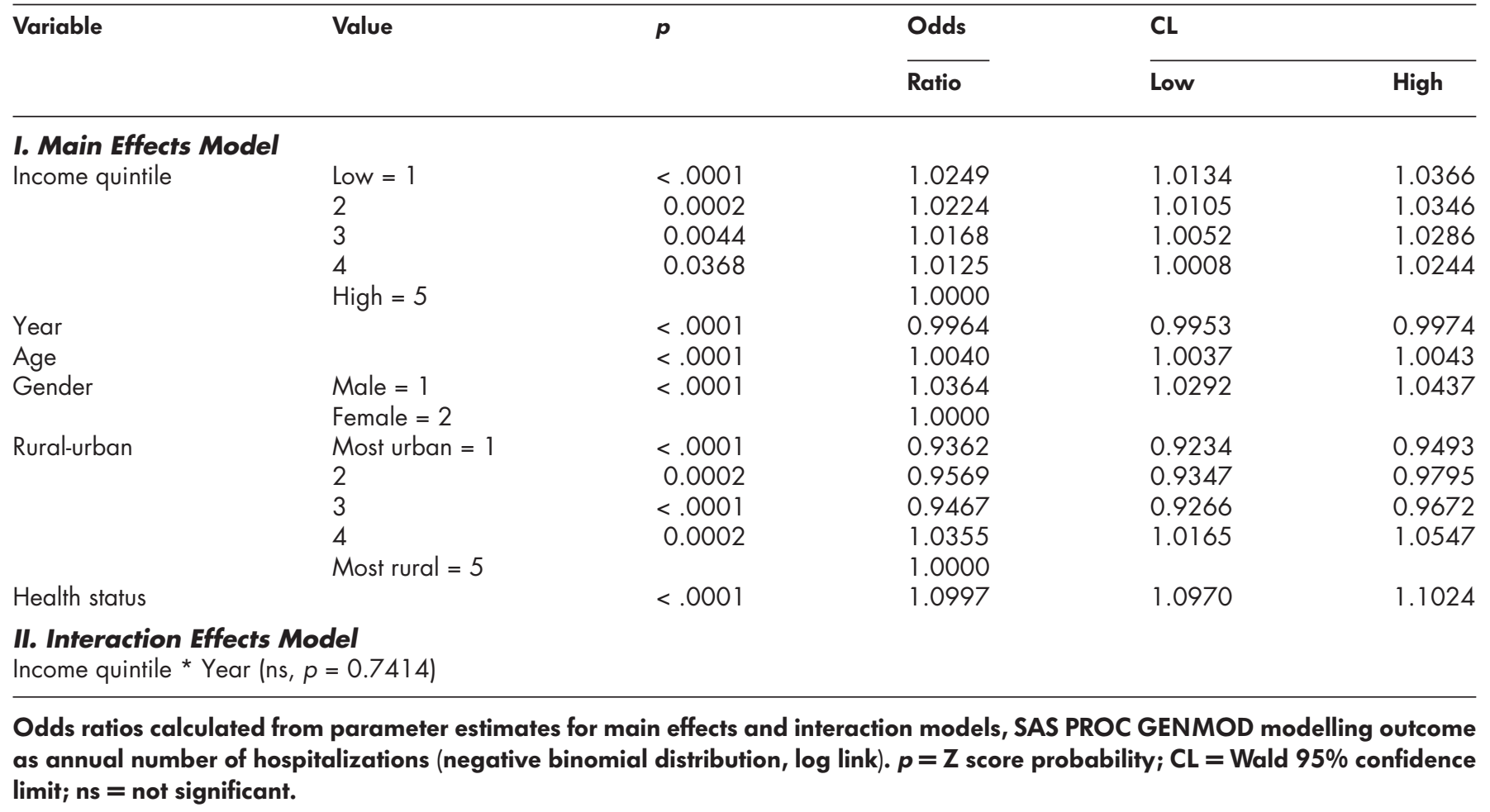


Table 8: Hospital length of stay conditional on use

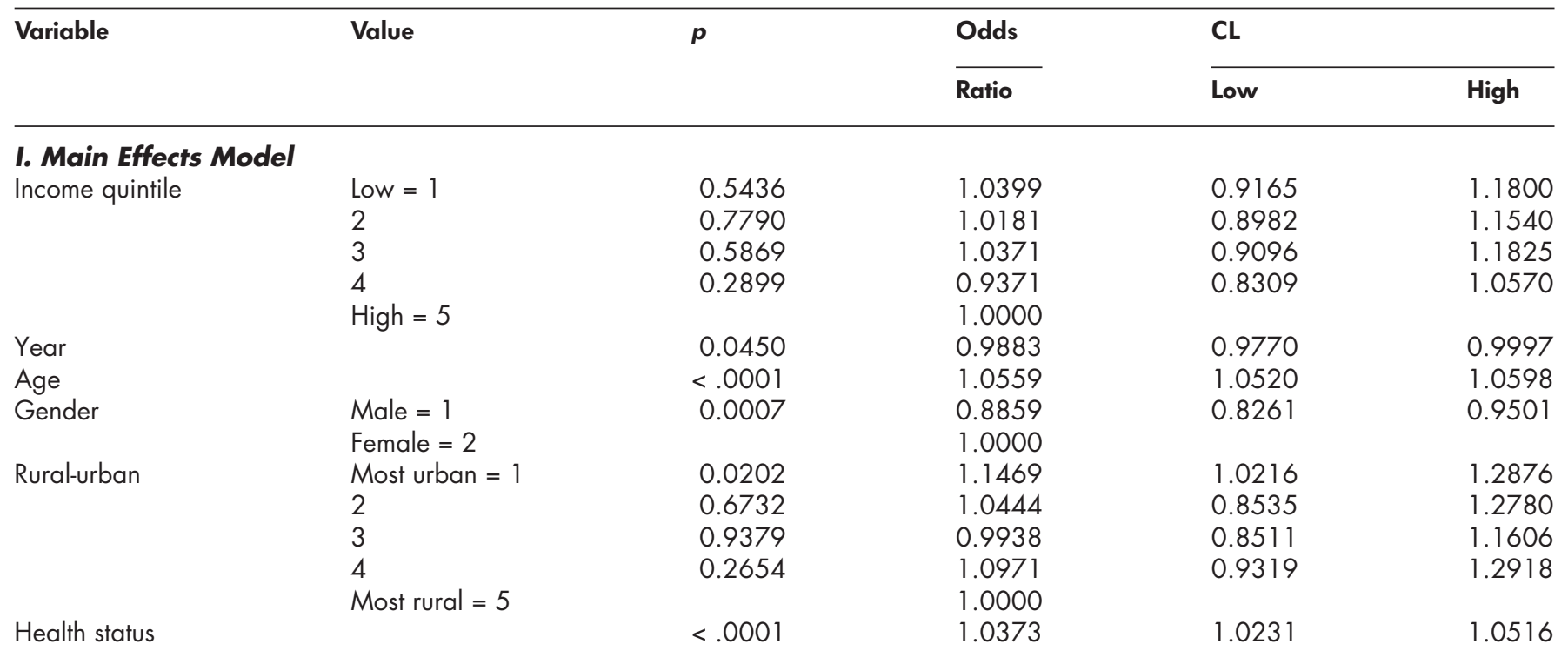

\section{Interaction Effects Model}

Income quintile * Year (ns, $p=0.3015$ )

Odds ratios calculated from parameter estimates for main effects and interaction models, SAS PROC GENMOD modelling outcome as annual number of nights in hospital (negative binomial distribution, log link). $p=Z$ score probability; $C L=W a l d ~ 95 \%$ confidence limit; ns = not significant.

older adults specifically. In past research, such findings have been interpreted as indicative of a mixed pattern of inequities - that is, pro-rich inequities in access to GP and specialist care accompanied by pro-poor inequities in inpatient hospital care and extent of (GP, hospital) care. Pro-rich inequities in access to GPs have been referred to as minor (e.g., McGrail, 2008) whereas inequities in specialist services are widely regarded as problematic (Curtis \& MacMinn, 2008; Hurley \& Grignon, 2006; van Doorslaer et al., 2004). Yet access to specialists tends to require GP referral, at least for the initial visit (Dunlop et al., 2000). As well, decisions regarding hospitalization are generally made by physicians (GPs and specialists) rather than patients.

However, findings indicating pro-poor inequities in inpatient hospital care would seem to counter this trend. One possible explanation for this is that greater inpatient hospital care is, in some ways, also a consequence of lesser access to primary and specialist care. For example, as Curtis and MacMinn (2008, p. 83) have noted, "at least some of the seeming advantages seen among individuals from lower SES circumstances are the result of conditions that are treatable or controllable with the provision of adequate primary care. Thus, equitable primary care is an avenue to avoid more expensive forms of treatment as well as an issue of fairness." Alternatively, it may also reflect differences in the types of hospital care (and potentially, other forms of health care as well) used across socioeconomic groups, with lower income groups relying more heavily on acute inpatient care while higher income groups make greater use of alternative services. Notably, a growing trend towards higher socioeconomic status (SES) groups using increasingly more day surgery and outpatient care has also been reported (see Curtis \& MacMinn, 2008; McGrail, 2008), with lower income groups relying more heavily on emergency hospitalizations (see Glazier, Tepper, Agha, \& Moineddin, 2006).

A major contribution of this study has been its longitudinal focus. It not only confirmed many of the findings reported within previous cross-sectional studies, but also revealed that temporal trends are important to consider as well, and that these differed in some important ways across income groups. Although year had little impact on whether or not people accessed GP services, it had a consistently significant impact on the number of visits made conditional on use as well as on access to and volume of specialist and hospital services used. Over time, more people used specialists' services and those who accessed GPs and specialists made more visits to them. Conversely, fewer people accessed inpatient hospital services, and those who did, accessed them less frequently.

Our findings revealed that the declines in access to services that took place in conjunction with health care reforms were more likely to involve those services (i.e., inpatient hospital care) on which those in lower income groups were the most likely to rely. Furthermore, in some 
instances, these disparities increased over time. Indeed, our findings revealed that pro-rich income disparities in access to GPs and specialists increased over the course of the decade while declines in access to hospital services were similar across income groups. Past studies that have focused on aggregate trends in hospital services alone have sometimes interpreted findings such as the latter to indicate that the income gradient in the hospital sector has been preserved despite overall reductions in care (e.g., see Brownell, Roos, \& Roos, 2001). However, when changes in access to hospital care are situated within a broader health care context that includes GP and specialist services, this conclusion seems less clear. Overall, findings indicating that generalized declines in access to hospital care have been accompanied by increasing income-related disparities in access to physician (GP, specialist) services would seem to point to increasing inequities in access to care within the context of Canada's universal publicly funded health care system.

Could it be that the declines evident in equitable access to medical care services were compensated for by greater access to publicly funded community-based home care services (e.g., home support services, home nursing care)? Home support services in particular are means-tested in British Columbia and, consequently, could be used to compensate for declines in access to physician and hospital services among those in lower income groups. In addition, there are indications that home care funding increased over the time period covered by this study, albeit at a lower rate than in other Canadian provinces (CIHI, 2007). However, available evidence suggests this is not the case. British Columbia not only had one of the lowest number of governmentsponsored home care users per capita of all the provinces, but also the number of users and number of home support claims decreased during the period of study (see Cohen, Murphy, Nutland, \& Ostry, 2005; McGrail et al., 2008; Penning, Brackley, \& Allan, 2006). According to McGrail et al. (2008), for example, from 1995-1996 to 2004-2005, the proportion of seniors using publicly funded home health services dropped by 30 per cent, due largely to a decrease in long-term (90+ days) home care use. Moreover, not only were lower income groups more likely to be long-term users of home care services, but also "this decrease in long-term home health service use was disproportionately greater among those in lower rather than higher income groups." (p. 9).

Interestingly, increasing inequities are less evident where volume of care among those with access to services is concerned. Despite lower (and increasingly lower) levels of access to GP services compared to those in the highest income quintile, those in lower income groups made more visits to GPs, and this differential increased over the course of the decade studied.
Findings of this nature suggest that despite being less likely to get in the door, once in, those with lower incomes received a greater volume of care than were those with the highest income levels. One possible explanation for such findings is that they reflect the impact of declines in access to inpatient hospital care observed during the same period. In other words, it may be that those who might otherwise have been hospitalized (or in hospital for longer periods) instead received more extensive care from GPs. Thus, primary care may have been used to substitute for the declining access to hospital services upon which those with lower incomes previously relied most heavily.

In concert with other researchers, our findings revealed that health and social factors other than income also were important determinants of health service contact and volume of use. As would be expected, in nearly all cases, poorer health status was associated with increased likelihood of service receipt as well as a greater volume of care conditional on receipt. The finding that age, gender, and rural-urban residence were important determinants of both access and volume of service use regardless of health need defined on the basis of chronic conditions in the models suggests that service utilization is not a function of this aspect of health status alone, but that, rather, utilization also varies in association with social structural location and social context (within which other health needs may also be embedded). Older adults, women, and those living in more urban areas of the province were more likely to access GP and specialist services, and also made more visits to GPs than others. Once hospitalized, older adults and women also spent more time in hospital. Yet males (along with older adults and those living in more urban areas) made more visits to specialists while those living in more-rural areas (along with males and older adults) were more likely to access inpatient hospital care and to be hospitalized more often.

It is possible that the emergence of these factors, to some extent at least, reflects the imperfect measurement of health status employed within our analyses. Our measure of health status was limited to co-morbid chronic conditions. Although measurement of chronic conditions is particularly appropriate when focusing on an older population, a broader set of health status indicators (e.g., that includes self-assessed health and acute conditions) might more accurately reflect the health care needs of those studied. For example, it has been suggested that low income groups tend to have more complex health needs than others, raising the added possibility that the implications of imperfections in measurement may not be equivalent across groups (Lemstra, Mackenbach, Neudorf, \& Nannapaneni, 2009). Also, within our analyses, those who did not access the health care system at all are necessarily considered 
"healthy", a potentially inaccurate assumption. Yet the fact that our findings mirror those reported by other studies using various other measures of health nevertheless increases our confidence in their relevance.

Several other limitations should also be noted when interpreting the findings. As with any study conducted in a particular locale, generalizability may be somewhat restricted. The data employed for this study refer to one Canadian province during one particular period of time (1992-2002). Whether the trends observed within this province from 1992-2002 continued into the next decade requires further research. Comparisons across provinces are also needed. The Canada Health Act, as national legislation, requires that all provinces adhere to the same principles (of universality, public administration, comprehensiveness, portability, and accessibility) as a condition of federal health care funding. However, in Canada, health service delivery is ultimately a provincial responsibility; consequently, there is also variation in selected health system characteristics, particularly when it comes to spending per capita, public/private mix, and services outside of physician and hospital care (Allin, 2008). For example, British Columbia currently ranks comparatively high among Canadian provinces in terms of GP visits but low when it comes to hospital utilization (see Allin, 2008; Dunlop et al., 2000; Jiménez-Rubio, Smith, \& van Doorslaer, 2008); such differences are likely the result of provincial government decision-making.

With regard to measurement, our analyses were necessarily restricted to health services that are covered by Medicare, yet this is likely where equitable access to health care is the greatest. As well, data on physician utilization were limited to services provided by physicians who were paid on a fee-for-service basis and therefore excluded services that were paid for in other ways (e.g., salaries, contracts). To date, alternative payment arrangements typically represent less than 10 per cent of total payments to physicians; although the proportion is greater in some areas (e.g., northern regions) than others and reportedly, has been increasing in recent years (McGrail, 2008). For hospital use, we focused on inpatient care. Yet, as noted, whereas inpatient care may be declining, outpatient care appears to be increasing, with some researchers reporting a trend towards higher SES groups obtaining more outpatient care (Curtis \& MacMinn, 2008). We were also restricted with regard to the specific social and health factors that could be included in the analyses; thus, other potentially important factors such as education, work status, ethnicity, race, and access to social supports (not available within the datasets used) could not be included. In addition, we necessarily relied on an ecological income measure that may well underestimate the actual incomeservice use relationship. Finally, our analyses did not take into account the impact of one type of care on the utilization of another despite suggestions regarding the importance of such factors.

These and other limitations attest to the need for further research to be conducted. In particular, there appears to be a need for longitudinal research that accounts for the services provided by non-fee-for-service physicians, that differentiates among various types of hospital care (e.g., inpatient, outpatient, emergency, extended care, avoidable vs. non-avoidable hospitalizations), and that also situates changes in the utilization of medical services (GP, specialist, and hospital care) in the context of changes taking place in various other health services (for example, home care) available within both public and private care systems over more recent years. In the end, equity is not about ensuring access to an ever-shrinking public care system, but rather, about overall access to health care resources. Such research needs to consider the coverage of a broader range of services (including home care, drug coverage, and services covered by supplemental insurance) which are likely to affect utilization and therefore influence overall equity in care.

Notwithstanding the need for further research, our findings have implications for health care policy as well. First, they would seem to counter suggestions to the effect that "medically necessary doctor and hospital services remain effectively insulated from competitive market forces in Canada since most continue to be fully funded by government under the umbrella of universal health insurance (Medicare)" (Randall \& Williams, 2006, p. 1595). Thus, our findings once again suggest that a publicly funded health care system should not be considered as a guarantee of equitable access to care even when it comes to those services, such as physician and hospital care, with universal coverage. Instead, as noted by Eyles et al. (1995, p. 330) following their assessment of trends in physician utilization that took place during the early years (1985 to 1991) of contemporary health care reform: "As cost-containment policies continue to dominate and health care reforms arising from these policies are introduced, there is the potential for the narrower goals of these particular policies to be achieved at the cost of the erosion of the income-free basis of access to services." Our results suggest that this may well be taking place. Evidence indicating that income inequities are increasing is challenging the equity principles underlying Canada's publicly funded health care system.

\section{Note}

1 The health system reform and public-sector expenditure trends observed in British Columbia appear similar to those evident in other provinces and Canada as a whole (Barer et al., 2003; CIHI, 2014). Reflecting these trends, the 
number of GPs and family practitioners (FPs) as well as specialists per capita declined steadily from 1992-1993 through 1997 and subsequently began to increase once again (CIHI, 2004, 2006). In contrast, hospital bed capacity continued to decline throughout the 11-year period. From 1991-1992 to 1996-1997, short-stay hospital beds reportedly declined by 30 per cent whereas acute-care beds per 1,000 population declined by 28.8 per cent (Sheps et al., 2000). From 1997-1998 through 2001-2002, bed capacity continued to decline, albeit at a somewhat slower pace. Overall, British Columbia reportedly experienced a 42 per cent decrease in acute-care bed capacity per 1,000 population between 1991-1992 and 2001-2002 (BCMA, 2008) followed by a subsequent 15 per cent decrease between 2001-2002 and 2010-2011 (BCMA, 2011).

\section{References}

Allin, S. (2008). Does equity in healthcare use vary across Canadian provinces? Healthcare Policy, 3(4), 83-99.

Allin, S., Grignon, M., \& Le Grand, J. (2010). Subjective unmet need and utilization of health care services in Canada: What are the equity implications? Social Science $\mathcal{E}$ Medicine, 70, 465-472.

Armstrong, P., Armstrong, H., Bourgeault, I. L., Choiniere, J., Lexchin, J., Mykhalovskiy, E., et al. (2003). Market principles, business practices and health care: Comparing the U.S. and Canadian experiences. International Journal of Canadian Studies, 28, 13-38.

Asada, Y., \& Kephart, G. (2007). Equity in health service use and intensity of use in Canada. BMC Health Services Research, 7, 41.

Badgley, R. (1991). Social and economic disparities under Canadian health care. International Journal of Health Services, 21, 659-671.

Barer, M. L., Morgan, S. G., \& Evans, R. G. (2003). Strangulation or rationalization? Costs and access in Canadian hospitals. Longwoods Review, 1(4), 10-19.

Benoit, C., Zadoroznyj, M., Hallgrimsdottir, H., Treloar, A., \& Taylor, K. (2010). Medical dominance and neoliberalisation in maternal care provision. Social Science $\mathcal{E}$ Medicine, $71,475-481$.

Birch, S., \& Abelson, J. (1993). Is reasonable access what we want - implications of, and challenges to, current Canadian policy on equity in health-care. International Journal of Health Services, 23(4), 629-653.

Birch, S., Eyles, J., \& Newbold, K. B. (1993). Equitable access to health care: Methodological extensions to the analysis of physician utilization in Canada. Health Economics, 2, 87-101.

Birch, S., \& Gafni, A. (2005). Achievements and challenges of Medicare in Canada: Are we there yet? Are we on course? International Journal of Health Services, 35, 443-463.

British Columbia Medical Association (BCMA) (2008). Improving access to acute care services: A policy paper by
$B C^{\prime}$ 's physicians. Vancouver, BC: Author. https://www. doctorsofbc.ca/sites/default/files/acute_care_0.pdf (accessed: March 9, 2015)

BCMA (2011). Improving access to acute care services: Policy statement. Vancouver, BC: Author. https://www.doctorsofbc.ca/sites/default/files/improving_access_to_ acute_care_services_-_july_2011.pdf (Accessed 9 March 2015)

Brownell, M. D., Roos, N. P., \& Roos, L. L. (2001). Monitoring health reform: A report card approach. Social Science $\mathcal{E}$ Medicine, 52, 657-670.

Broyles, R. W., Manga, P., Binder, D. A., Angus, D. E., \& Charette, A. (1983). The use of physician services under a national health insurance scheme: An examination of the Canada Health Survey. Medical Care, 21, 1037-1054.

Canadian Institute for Health Information (2000). Health care in Canada 2000: A first annual report. Ottawa, ON: Author.

Canadian Institute for Health Information (2004). Health personnel trends in Canada, 1993-2002. Ottawa, ON: Author.

Canadian Institute for Health Information (2006). Health personnel trends in Canada, 1995-2004. Ottawa, ON: Author.

Canadian Institute for Health Information (2007). Publicsector expenditures and utilization of home care in Canada: Exploring the data. Ottawa, ON: Author.

Canadian Institute for Health Information (2008). Health care in Canada 2008. Ottawa, ON: Author.

Canadian Institute for Health Information (2014). National health expenditure trends, 1975 to 2014. Ottawa, ON: Author.

Canadian Medical Association (CMA) (2015). Canadian physician statistics: Physicians per 100,000 population by province/territory, 1986-2013. https://www.cma.ca/ En/Pages/canadian-physician-statistics.aspx (Accessed 9 March 2015).

Carriere, K. C., Roos, L. L., \& Dover, D. C. (2000). Across time and space: Variations in hospital use during Canadian health reform. Health Services Research, 35(2), 467-487.

Chan, B. T. B., \& Austin, P. C. (2003). Patient, physician, and community factors affecting referrals to specialists in Ontario, Canada. Medical Care, 41(4), 500-511.

Chamberlayne, R., Green, B., Barer, M. L., Hertzman, C., Lawrence, W. J., \& Sheps, S. B. (1998). Creating a population-based linked health database: A new resource for health services research. Canadian Journal of Public Health, 89, 270-273.

Charlson, M. E., Pompei, P., Ales, K. L., \& MacKenzie, C. R. (1987). A new method of classifying prognostic comorbidity in longitudinal studies: Development and validation. Journal of Chronic Disease, 40, 373-383.

Coburn, D. (2003). Globalization, neoliberalism and health. In R. Sandbrook (Ed.), Civilizing globalization. New York, NY: State University of New York Press. 
Coburn, D. (2010). Health and health care: A political economy perspective. In T. Bryant, D. Raphael, T. , \& M. Rioux (Eds.), Staying alive: Critical perspectives on health, illness and health care (2nd ed.). Toronto, ON: Canadian Scholars Press.

Cohen, M., Murphy, J., Nutland, K., \& Ostry, A. (2005). Continuing care renewal or retreat? $B C$ residential and home health care restructuring 2001-2004. Vancouver, BC: Canadian Centre for Policy Alternatives.

Curtis, L. J., \& MacMinn, W. J. (2008). Health-care utilization in Canada: Twenty-five years of evidence. Canadian Public Policy, XXXIV(1), 65-87.

Deber, R. B. (2003). Health care reform: Lessons from Canada. American Journal of Public Health, 93(1), 20-24.

DeCoster, C., Roos, N., \& Carriere, K. C. (1997). Inappropriate hospital use by patients receiving care for medical conditions: Targeting utilization review. Canadian Medical Association Journal, 157(7), 889-892.

Dunlop, S., Coyte, P. C., \& McIsaac, W. (2000). Socioeconomic status and the utilization of physicians' services: Results from the Canadian National Population Health Survey. Social Science E Medicine, 51(1), 123-133.

Enterline, P. E., Salter, V., McDonald, A. D., \& McDonald, J. C. (1973). The distribution of medical services before and after 'free' medical care: The Quebec experience. New England Journal of Medicine, 289, 1174-1178.

Eyles, J., Birch, S., \& Newbold, K. B. (1995). Delivering the goods? Access to family physician services in Canada: A comparison of 1985 and 1991. Journal of Health and Social Behavior, 36(4), 322-332.

Frenette, M., Green, D. A., \& Picot, G. (2004). Rising income inequality in the 1990s: An exploration of three data sources. Ottawa, ON: Statistics Canada.

Glazier, R. H., Tepper, J., Agha, M. M., Moineddin, R. (2006). Primary care in disadvantaged populations [Chapter 8]. In R. Upshur, J. Klein-Geltink, A. Leong, S. Maaten, S. Schultz, \& L. Wang (Eds.), Primary care: A practice atlas. Toronto, ON: Institute for Clinical Evaluative Studies.

Hall, W. H., Ramachandran, R., Narayan, S., Jani, A. B., \& Vijayakumar, S. (2004). An electronic application for rapidly calculating Charlson comorbidity score. BMC Cancer, 4, 94 .

Hanratty, B., Zhang, T., \& Whitehead, M. (2007). How close have universal health systems come to achieving equity in use of curative services? A systematic review. International Journal of Health Services, 37(1), 89-109.

House of Commons, Canada (1984). Canada health act. Ottawa, ON: Ministry of Supply and Services.

Hurley, J., \& Grignon, M. (2006). Income and equity of access to physician services. Canadian Medical Association Journal, 174(2), 187-88.
Jiménez-Rubio, D., Smith, P. C., \& van Doorslaer, E. (2008). Equity in health and health care in a decentralised context: Evidence from Canada. Health Economics, 17, 377-392.

Lasser, K. E., Himmelstein, D. U., \& Woolhandler, S. (2006). Access to care, health status, and health disparities in the United States and Canada: Results of a cross-national population-based survey. American Journal of Public Health, 96, 1-8.

Lemstra, M., Mackenbach, J., Neudorf, C., \& Nannapaneni, U. (2009). High health care utilization and costs associated with lower socio-economic status: Results from a linked dataset. Canadian Journal of Public Health, 100(3), 180-183.

Macdonald, J., Raphael, D., Labonte, R., Colman, R., Torgerson, R., \& Hayward, K. (2009). Income and health in Canada: Canadian researchers' conceptualizations make policy change unlikely. International Journal of Health Services, 39(3), 525-543.

Manga, P. (1987). Equity of access and inequalities in health status. In D. Coburn (Ed.), Health and Canadian Society (pp. 637-648). Markham, ON: Fitzhenry \& Whiteside.

Manga, P., Broyles, R. W., \& Angus, D. E. (1987). The determinants of hospital utilization under a universal public insurance program in Canada. Medical Care, 25, 658-670.

McGrail, K. M. (2008). Income-related inequities: Crosssectional analyses of the use of Medicare services in British Columbia in 1992 and 2002. Open Medicine, 2(4), E3-E10.

McGrail, K. M., Broemeling, A.-M., McGregor, M. J., Salomons, K., Ronald, L. A., \& McKendry, R. (2008). Home health services in British Columbia: A portrait of users and trends over time. Vancouver, BC: UBC Centre for Health Services and Policy Research. http://www. chspr.ubc.ca/sites/default/files / publication_files / chspr08-15.pdf (Accessed 9 March 2015).

McIsaac, W. J., Goel, V., \& Naylor, C. D. (1997). Socioeconomic status and visits to physicians by adults in Ontario, Canada. Journal of Health Services Research $\mathcal{E}$ Policy, 2, 94-102.

Mustard, C. A., Derksen, S., Berthelot, J. M., \& Wolfson, M. (1999). Assessing ecologic proxies for household income: A comparison of household and neighbourhood level income measures in the study of population health status. Health Place, 5(2), 157-171.

Nabalamba, A., \& Millar, W. J. (2007). Going to the doctor. Health Reports, 18(1), 23-35.

Newbold, K. B. (2009). Health care use and the Canadian immigrant population. International Journal of Health Services, 39(3), 545-565.

Penning, M. J., Brackley, M. E., \& Allan, D. E. (2006). Home care and health reform: Changes in home care utilization 
in one Canadian province, 1990-2000. The Gerontologist, 46(6), 744-758.

Pitblado, J. R., Pong, R. W., Irvine, A., Nagarajan, K. V., Sahai, V., Zelmer, J., et al. (1999). Assessing rural health: Toward developing health indicators for rural Canada. Ottawa, ON: Health Canada.

Quan, H., Sundararajan, V., Halfon, P., Fong, A., Burnand, B., \& Luthi, J. C., et al. (2005). Coding algorithms for defining comorbidities in ICD-9-CM and ICD-10 administrative data. Medical Care, 43(11), 1130-1139.

Racher, F. E., Vollman, A. R., \& Annis, R. C. (2004). Conceptualizations of "rural": Challenges and implications for nursing research. Online Journal of Rural Nursing and Health Care, 4(2). [Online]. http://www.rno.org/journal/issues/ Vol-4/Racher_article.htm

Randall, G. E., \& Williams, A. P. (2006). Exploring limits to market-based reform: Managed competition and rehabilitation home care services in Ontario. Social Science $\mathcal{E}$ Medicine, 62, 1594-1604.

Reid, R., Evans, R., Barer, M., Seps, S., Kerluke, K., McGrail, K., et al. (2003). Conspicuous consumption: Characterizing high users of physician services in one Canadian province. Journal of Health Services Research E Policy, 8(4), 215-224.

Roos, L. L., Mustard, C. A., Nicol, J. P., McLerran, D. F., Malenka, D. J., Young, T. K., et al. (1993). Registries and administrative data: Organization and accuracy. Medical Care, 31(3), 201-212.

Roos, L. L., Nicol, J. P., \& Cageorge, S. M. (1987). Using administrative data for longitudinal research-Comparisons with primary data collection. Journal of Chronic Diseases, 40(1), 41-49.

Roos, N., Burchill, C., \& Carriere, K. (2003). Who are the high hospital users? A Canadian case study. Journal of Health Services Research \& Policy, 8(1), 5-10.

Schneeweiss, S., Seeger, J. D., Maclure, M., Wang, P. S., Avorn, J., \& Glynn, R. J. (2001). Performance of comorbidity scores to control for confounding in epidemiologic studies using claims data. American Journal of Epidemiology, 154(9), 854-864.

Sheps, S. B., Reid, R. J., Barer, M. L., Krueger, H., McGrail, K. M., Green, B., et al. (2000). Hospital downsizing and trends in health care use among elderly people in British Columbia. CMAJ, 163(4), 397-401.
Sin, D. D., Svenson, I. W., \& Man, S. F. (2001). Do area-based markers of poverty accurately measure personal poverty? Canadian Journal of Public Health, 92, 184-187.

Stabile, M. (2001). Private insurance subsidies and public health care markets: Evidence from Canada. Canadian Journal of Economics, 34, 921-942.

Statistics Canada (1997). GeoRef users guide: 1996 censusReference products. Catalogue No. 92F0085XCB. Ottawa, ON: Author.

Teeple, G. (2000). Globalization and the decline of social reform. Aurora, ON: Garamond Press.

Thorlby, R. (2011). Managing health reform through an economic downturn. London, England: The Nuffield Trust.

van Doorslaer, E., Masseria, C., \& Koolman, X. (2006). Inequalities in access to medical care by income in developed countries. Canadian Medical Association Journal, 174(2), 177-183.

van Doorslaer, E., Masseria, C., \& OECD Health Equity Research Group (2004). Income-related inequality in the use of medical care in 21 OECD countries. OECD Health Working Paper No. 14. Paris, France: OECD.

Watson, D. E., Black, C., Peterson, S., Mooney, D., \& Reid, R. J. (2006). Who are the primary health care physicians in British Columbia? 1996/97-2004/05. Vancouver, BC: Centre for Health Services and Policy Research, University of British Columbia.

Watson, D. E., Heppner, P., Reid, R., Bogdanovic, B., \& Roos, N. (2005). Use of physician services by older adults: $1991 / 1992$ to $2000 / 2001$. Canadian Journal on Aging, 24(Suppl 1), 29-36.

Williams, A. P. (2007). Strategic purchasing in home and community care across Canada: Coming to grips with "what" to purchase. Healthcare Papers, 8, 93-103.

Williams, A. P., Deber, R., Barenek, P., \& Gildiner, A. (2001). From Medicare to home care: Globalisation, state retrenchment and the profitization of Canada's health-care system. In P. Armstrong, D. Armstrong, \& D. Coburn (Eds.), Unhealthy times: Political economy perspectives on health and health care (pp. 7-30). Toronto, ON: Oxford University Press.

Yip, M. A., Kephart, G., \& Veugelers, P. J. (2002). Individual and neighbourhood determinants of health care utilization: Implications for health policy and resource allocation. Canadian Journal of Public Health, 93(4), 322-332. 